Neurosurg Focus 25 (3):E13, 2008

\title{
Epilepsy surgery and tuberous sclerosis complex: special considerations
}

\author{
A review
}

Robert J. Bollo, M.D., ${ }^{1}$ Stephen P. Kalhorn, M.D., ${ }^{1}$ Chad Carlson, M.D., ${ }^{2}$
Veronique Haegeli, PH.D., ${ }^{1}$ Orrin DeVinSky, M.D., ${ }^{2}$ AND Howard L. Weiner, M.D. ${ }^{1}$

${ }^{1}$ Department of Neurosurgery and ${ }^{2}$ Comprehensive Epilepsy Center, Department of Neurology, New York University School of Medicine and New York University Langone Medical Center, New York, New York

\begin{abstract}
Epilepsy surgery for medically refractory seizures among patients with tuberous sclerosis complex (TSC) is a wellaccepted treatment option. Many epilepsy centers around the world have published their experience over the past several years, supporting the idea that the best seizure control is obtained when a single tuber and associated epileptogenic zone is documented and targeted surgically. Recent advances in imaging and physiological techniques that reveal the epileptogenic zone have been used successfully in children with TSC who are being evaluated for surgery. As a result, a number of different surgical strategies have emerged, each reflecting the experience, strengths, and referral biases of the individual treating teams. Experience suggests that some patients with TSC who present with seizures that are difficult to localize and do not meet the classic selection criteria for epilepsy surgery may, nevertheless, benefit from sugery. Tuberectomy alone is often not sufficient for obtaining seizure control. Intracranial electrode recordings performed in a large number of children with TSC undergoing epilepsy surgery have raised new questions about the relationship of the cortical tuber to the epileptogenic zone in TSC. A careful assessment of the risks and benefits of any surgical strategy, compared with those associated with continued refractory epilepsy, should be considered by the treating team in conjunction with the patient's family. Epilepsy surgery has not only benefited many children with TSC, but it also facilitates the understanding of epileptogenesis in TSC. (DOI: 10.3171/FOC/2008/25/9/E13)
\end{abstract}

\section{KEY Words • epilepsy • neurosurgery • tuberous sclerosis}

$$
\mathrm{T}
$$
UBEROUS sclerosis complex is a neurocutaneous disorder affecting multiple organ systems, including the brain, heart, kidneys, and skin. ${ }^{19,54,55,59,62,71,73}$ This disorder has a variable penetrance and a wide range of phenotypes, and it is believed to affect between 1:5000 and 1:10,000 individuals. ${ }^{38,47,49,64}$ Although TSC is transmitted in an autosomal dominant fashion, two-thirds of cases are sporadic, resulting from spontaneous mutations or mosaicism. ${ }^{36,58,70}$ Two major disease-causing genes have been identified: TSC1 and TSC2, which code for the proteins hamartin and tuberin, respectively. ${ }^{30,60}$ Both hamartin and tuberin are widely expressed under physiological conditions in normal tissues, interact to form a heterodimer, and regulate the cell cycle. ${ }^{66,68,69}$ Pathological mutations produce changes in protein structure, preventing heterodimerization

Abbreviations used in this paper: $\mathrm{AMT}=-{ }^{11} \mathrm{C}-$ methyl-serotonin; $\mathrm{EEG}=$ electroencephalography; FDG $=\left[{ }^{18} \mathrm{~F}\right]$ fluorodeoxyglucose; MEG = magnetoencephalography; SISCOM = Subtraction ictal SPECT coregistered to MR imaging; TSC = tuberous sclerosis complex. of hamartin and tuberin, resulting in functional changes manifested as the TSC phenotype..$^{22,45,46}$

The diagnosis of TSC is established by clinical criteria. ${ }^{13}$ The clinical phenotype of TSC was usually described as Vogt's triad of seizures, mental retardation, and facial angiofibromas. ${ }^{62}$ However, this triad is seen in $<50 \%$ of patients with TSC, and the current diagnosis of TSC requires the presence of major and minor clinical features agreed on at the Tuberous Sclerosis Complex Consensus Conference in $1998 .{ }^{54,55}$ These include ash leaf spots, facial angiofibromas in a malar pattern, retinal hamartomas, cardiac rhabdomyoma, and renal angiomyolipoma. The central nervous system is affected by cortical heterotopias and cortical tubers, subependymal nodules or "candle guttering," and subependymal giant cell astrocytomas. ${ }^{55}$ Approximately $90 \%$ of patients with TSC suffer from seizures, and epilepsy is the leading cause of morbidity; most seizures commence before the age of 2 years. ${ }^{25,72}$

Based on the experience of several investigators over the last 20 years, the efficacy of surgery is well established for controlling seizures in patients with TSC with concordant and localized neuroimaging and electrophysiological 
data. ${ }^{3,5,8,18,26-28,34,35,37,41,42,52,57,75}$ Independent investigators at a variety of international comprehensive epilepsy centers have come to the conclusion that epilepsy surgery is an excellent treatment option for the appropriately selected child with TSC. $3,5,8,18,26-28,34,35,37,41,52,57,75$ The goal of epilepsy treatment in TSC, as in the treatment of other types of epilepsy, is the elimination of seizures as soon as possible to optimize cognitive development and improve behavior and quality of life. ${ }^{14}$

It is well recognized that persistent seizures may have a detrimental effect on cognitive development, and epilepsy surgery can impact on this situation favorably. ${ }^{39}$ Ultimately, the decision to proceed to surgical treatment depends on an analysis of the risk-benefit profile for each patient. At the time of referral for surgery there are no other viable options and the patient is developmentally losing ground. Nonoperative therapy with multiple antiepileptic medications has failed, and the patient has not responded to a ketogenic diet or vagal nerve stimulation..$^{11}$

\section{Preoperative Evaluation}

As in all epilepsy surgery, the goal of the preoperative evaluation of the child with TSC is first to delineate the epileptogenic zone, and second to determine the functional status of the cortex in and around the epileptogenic zone to assess the safety and risks of resection. The evaluation of children with TSC typically consists of a detailed family, birth, and personal history, physical examination, neuropsychiatric testing, routine structural imaging with MR and CT imaging, electrophysiological studies including interictal EEG and prolonged video-EEG monitoring, and noninvasive functional mapping studies including MEG, PET, and ictal and periictal SPECT. In a large proportion of patients with TSC and focal epilepsy, multiple cortical lesions on MR images present the challenge of identifying the epileptogenic tuber(s). ${ }^{25}$ Several noninvasive neuroimaging techniques have demonstrated substantial promise and warrant further discussion.

Magnetoencephalography may be especially useful in identifying the epileptogenic tuber in patients with TSC and focal seizures, and it has demonstrated high sensitivity and specificity for predicting the epileptogenic zone based on surgical outcome. ${ }^{23,25,33}$ The presence of single clusters compared with multiple clusters or scattered bilateral discharges may differentiate patients with a single, primary ictal onset zone from those with multiple or bilateral ictal onset zones underlying a more diffuse epileptogenic network. ${ }^{23}$ Furthermore, MEG and video-EEG techniques are complementary, due to the differential sensitivity to radial spike activity from the cortical surface compared with tangential discharges at the depth of a sulcus or deep within the sylvian fissure. ${ }^{25}$

Positron emission tomography uses radiolabeled tracers to image cerebral perfusion $\left(\left[{ }^{15} \mathrm{O}\right] \mathrm{H}_{2} \mathrm{O}\right)$, glucose and protein metabolism (FDG and ${ }^{11} \mathrm{C}$-methionine), and $\gamma$-aminobutyric acid receptor density ([$\left.{ }^{11} \mathrm{C}\right]$ flumazenil). ${ }^{15,31}$ Positron emission tomography images coregistered to MR images provide anatomical localization of regions of abnormal substrate metabolism, which often correlates with ictal onset zones. ${ }^{15}$ The relatively new tracer AMT, which images tryptophan metabolism and serotonin receptor density, has successfully distinguished epileptogenic and elec- trically silent tubers in small studies..$^{10,31,32,65}$ Periictal diffusion weighed MR imaging often shows restricted diffusion in the involved cortical region, and it may be useful in localizing epileptogenic cortex in patients with multiple anatomically distant tubers. ${ }^{56}$ Studies in children with TSC have suggested that the combination of hypometabolism on FDG-PET images and large apparent diffusion coefficient volumes on diffusion weighted images may have high specificity for epileptogenic tubers. ${ }^{9}$

Ictal SPECT, in which tracer injection is performed during a seizure, also demonstrates focal hyperperfusion corresponding to the ictal onset zone with sensitivity similar to FDG-PET. ${ }^{11,53}$ The SISCOM improves the sensitivity of SPECT by detecting regional differences between interictal and ictal perfusion. Preoperative SISCOM provides useful information for invasive electrode placement among children with multiple lesions, such as TSC. ${ }^{1}$

Invasive video-EEG is a highly sensitive modality for detection of the ictal onset zone in the presence of a focal lesion on structural MR images., ${ }^{7,50,61,77}$ Specific indications for invasive monitoring vary considerably between epilepsy centers. Generally, pediatric candidates have discordant noninvasive data, multifocal pathology, an ictal onset zone adjacent to eloquent functional regions, or a lesion with chronic seizures, where the ictal onset zone is often localized to cortex around the lesion. ${ }^{29}$ Patients with TSC and refractory seizures frequently meet many of these criteria. ${ }^{4}$

\section{Surgical Strategies}

Epilepsy surgery in the child with TSC requires special considerations. It is essential to emphasize that these are very difficult cases. Several surgical strategies have been proposed, each offering a unique set of advantages and disadvantages. ${ }^{2,9,10,75}$ No single approach should be considered optimal. Rather, using our own experience as an example, each approach reflects the philosophy and specific experience of a particular epilepsy center. A valuable benefit of our surgical experience has been the accumulation of electrophysiological recording data in vivo, which has provided insight into the underlying epileptogenesis in patients with TSC.

The first report of epilepsy surgery for TSC was in 1966 by Perot et al. ${ }^{52}$ from the Montreal Neurological Institute. Over the 40 years since that report, the published literature has consistently found that traditional resective epilepsy surgery can be very successful in reducing the seizure burden in carefully selected patients with TSC who harbor a single tuber and associated epileptogenic focus. . $^{3,5,8,18,26-}$ 28,34,35,37,41,52,57,75 Patients not meeting this selection criterion for surgery were offered a palliative approach, such as corpus callosotomy. ${ }^{18} \mathrm{~A}$ review of the TSC epilepsy surgery literature indicates that patients with a well-localized single tuber and corresponding epileptogenic zone are excellent surgical candidates, but children not fitting this profile are often excluded from operative treatment because a poor outcome was anticipated.

We believe this conclusion may reflect an intrinsic bias, with a potentially self-fulfilling prediction. In the rare TSC case characterized by a dominant single epileptogenic tuber, surgery is often curative (Fig. 1). The traditional operative approach of lesionectomy or "tuberectomy" consists of targeting the tuber alone. Therefore, the principal task of 


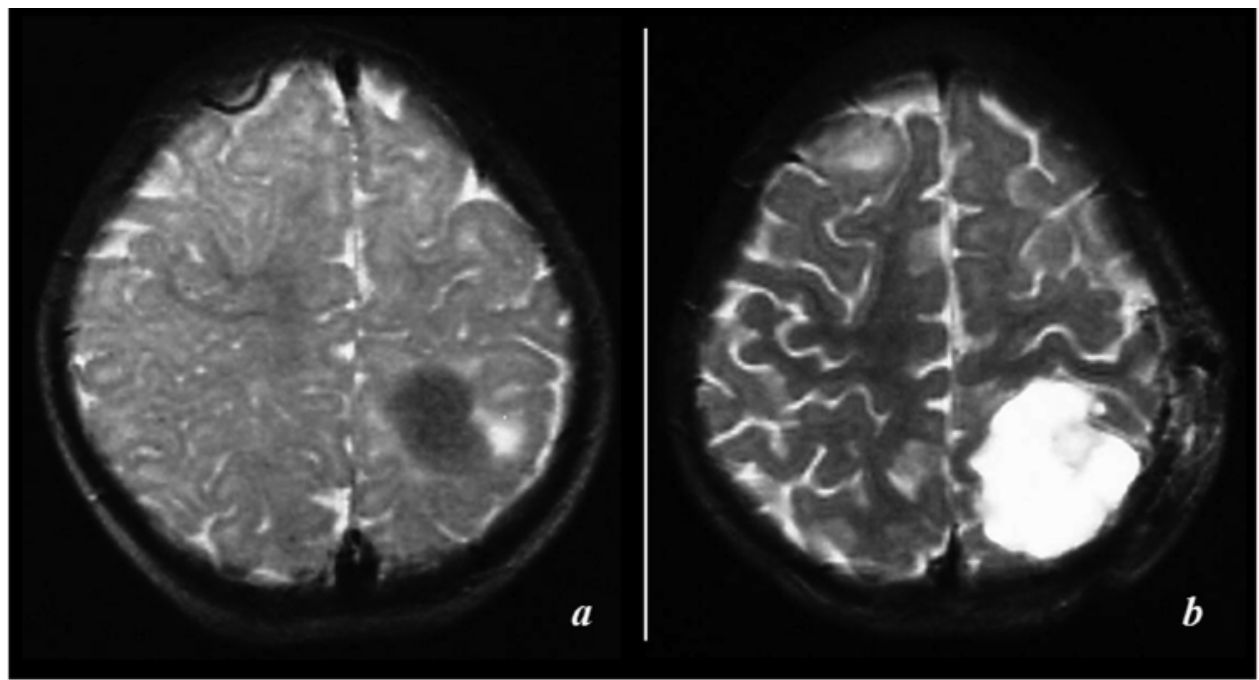

FIG. 1. Axial T2-weighted MR images obtained in a 1-year-old girl with TSC and medically refractory seizures. a: Preoperatively, a single, dominant calcified tuber is noted in the left hemisphere. b: Postoperative image after tuber resection.

the preoperative evaluation is to identify the tuber that was the source of the patient's clinical seizures. However, the clinician is more commonly confronted with a significantly more complex scenario (Fig. 2), such as the child who presents with multifocal epilepsy and multiple bilateral cortical tubers, many of which may be epileptogenic. This patient would be rejected for surgical consideration based on traditional criteria. In light of the paucity of effective treatment for these patients, we questioned whether patients with multiple potentially epileptogenic tubers in whom medical therapy failed might be candidates for an alternative surgical approach.

\section{Surgery for Multifocal Epilepsy in TSC}

In the context of the hypothesis that epilepsy in TSC is a network often manifested clinically by multifocal seizures ${ }^{24}$ we asked whether a strategic surgical intervention targeting a seemingly occult primary seizure focus could beneficially alter this network. Because tubers should cause partial epilepsy, we questioned whether patients with TSC might be harboring an undetected dominant seizure focus not seen on conventional testing. A review of the epilepsy surgery literature, in fact, supports this hypothesis: multifocal epilepsy is an observed phenotype of a primary seizure focus driving a complex epileptic network, and a "multifocal EEG" may mask a primary seizure focus. Some examples of this idea in the literature include temporal lobectomy in bilateral temporal epilepsy, hypothalamic hamartoma, infantile spasms due to focal cortical dysplasia, and congenital focal brain lesions associated with generalized EEG findings. ${ }^{12,20,21,79}$ The challenge is finding this prima-

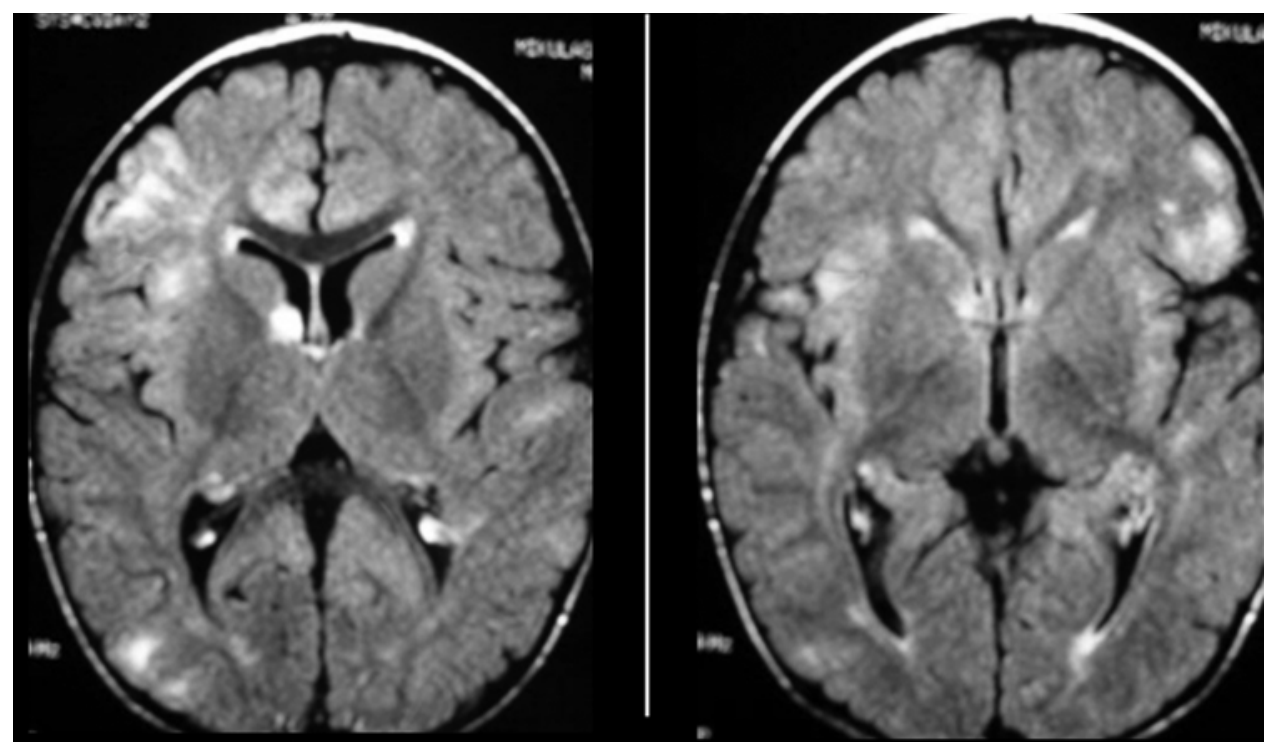

FIG. 2. Axial FLAIR MR images obtained in a patient with TSC. Note the multiple hyperintensities representing cortical tubers. 
R. J. Bollo et al.

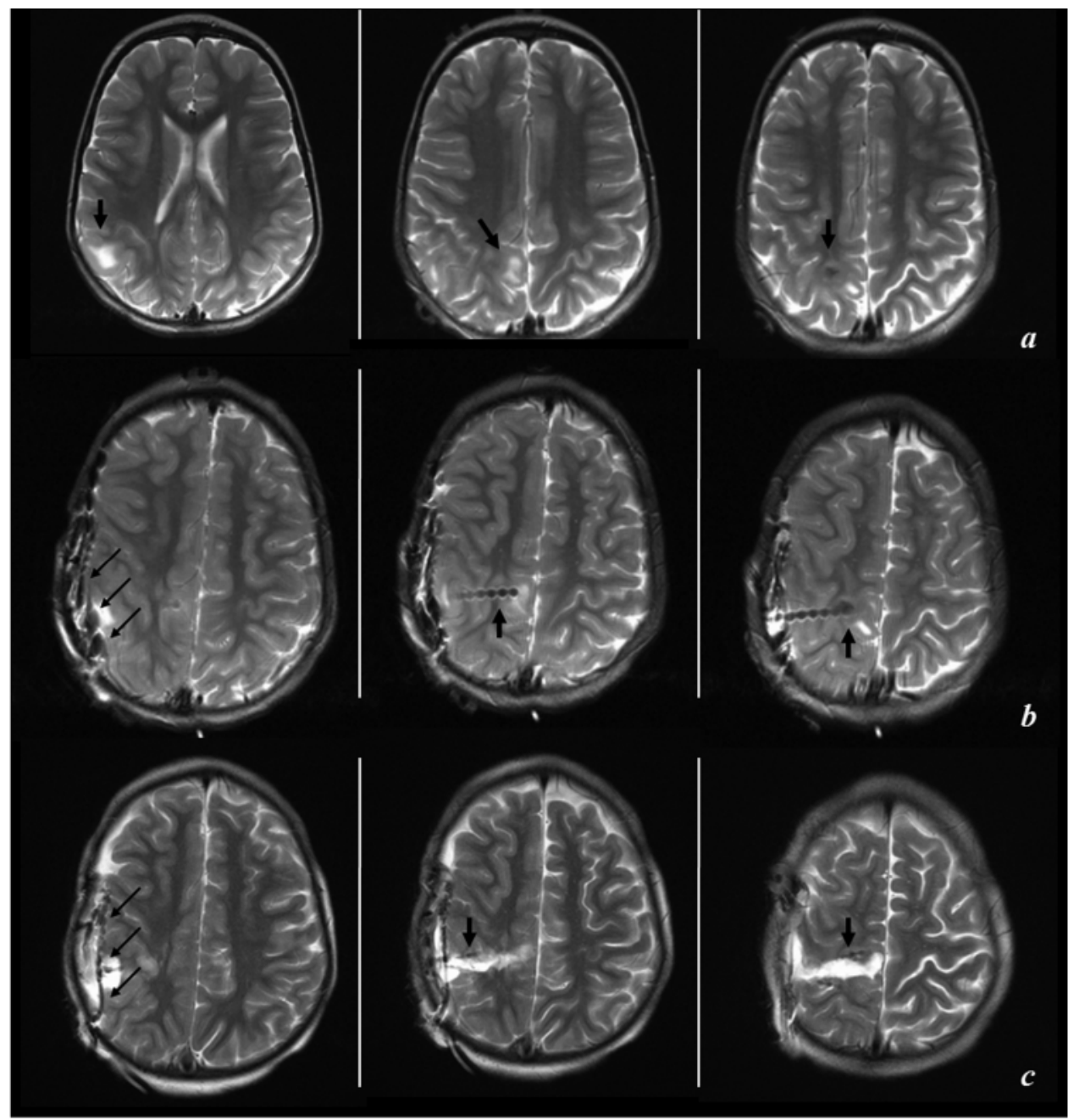

FIG. 3. Illustrative case. Axial T2-weighted MR images obtained in a 3.5-year-old patient with TSC and multifocal epilepsy. a: Preoperative images. Note large right central lateral tuber (arrow in left panel), smaller right posterior frontal mesial tuber (arrow in center panel), and right posterior frontal region of T2 signal hypodensity consistent with a calcified tuber (arrow in right panel). b: Images obtained after Stage 1. Note right posterior frontal grid overlying the lateral tuber (arrows in left panel) and depth electrode targeted to mesial tubers using frameless stereotaxis (arrows in center and right panels). c: Images obtained after Stage 2. Note the lateral grid overlying resection cavity of lateral tuber (arrows in left panel) and depth electrodes targeted to the anterior and posterior margins of the resection cavity (arrows in center and left panels).

ry focus, and advances in functional mapping and electrophysiological recording continue to improve and refine this endeavor.

Our initial surgical experience among patients with TSC was guided by this conceptual framework, and our goal was to reduce seizure and medication burden rather than seizure freedom. Therefore, we did not exclude patients who did not meet traditional surgical criteria. We were surprised and encouraged by several good outcomes among complex patients..$^{57,75}$ This included one patient who underwent bilateral resections of independent epileptogenic regions in nonhomologous cortical regions..$^{57}$ At 9-year follow-up, this child remains seizure free, supporting the notion that some children who do not fit traditional criteria for surgery may experience a good outcome with an acceptable treatment risk. This experience among others fostered an alternative approach to surgical treatment among selected children with TSC, particularly those with a poor quality of life who may not meet traditional surgical criteria.

This approach has evolved into a comprehensive strategy for the surgical management of TSC incorporating 3 main objectives. First, we strive to identify potential candidates at a young age. Children with TSC most often present with seizures very early in life. This epilepsy is often aggressive and is associated with developmental delay or regression. Improved seizure control may afford these patients significant developmental improvement. Indeed, evidence suggests that successful epilepsy surgery in TSC is related to a short duration of refractory epilepsy. Therefore, early identification of potential surgical candidates is critical for seizure control and optimal development. However, the published literature primarily contains reports on older children, $3,5,8,18,26-28,34,35,37,41,52,57,75$ with very few 

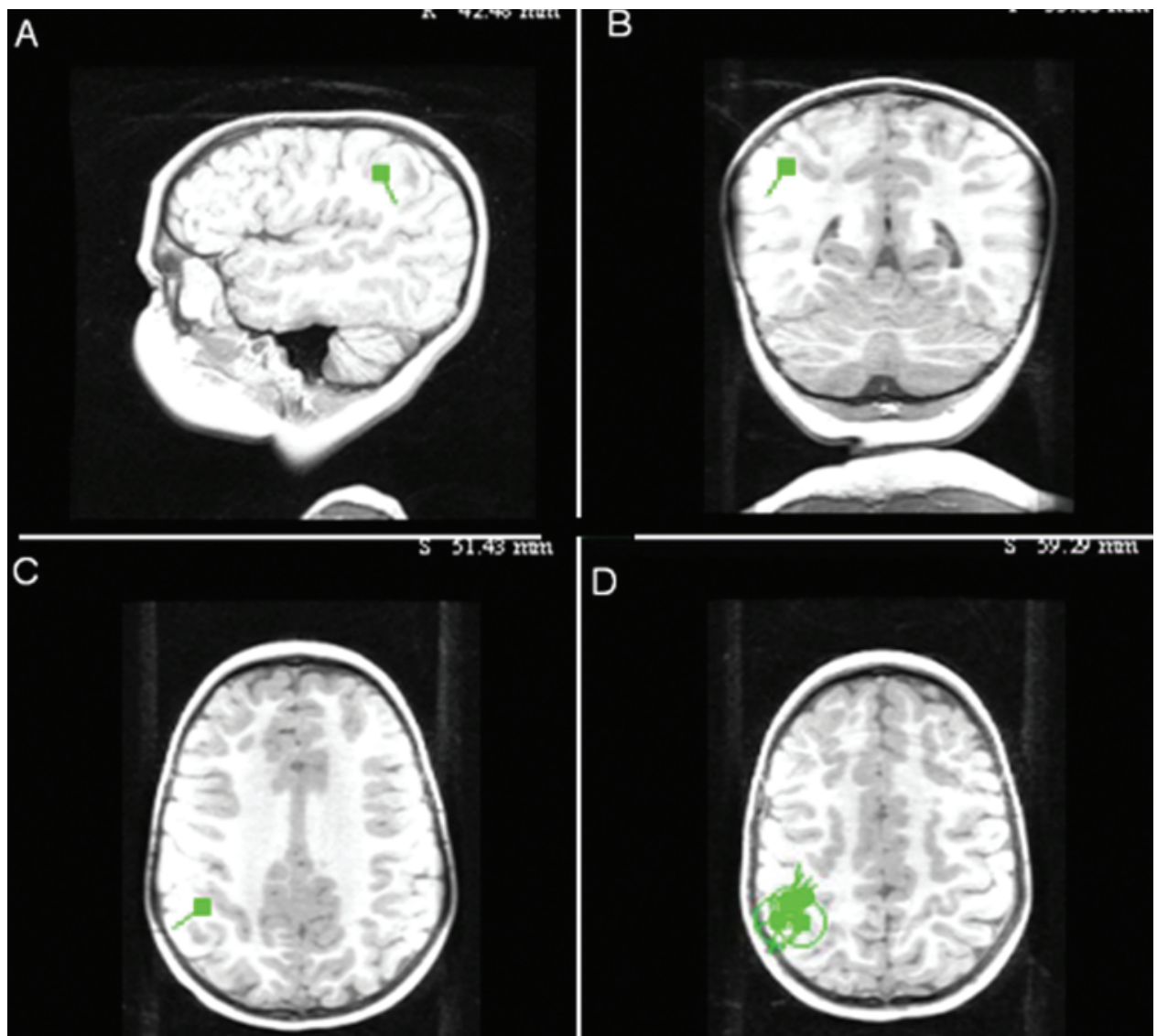

FIG. 4. Illustrative case. Sagittal (A), coronal (B), and axial (C) localizations of a single somatosensory evoked response (green areas) on MEG mapped to the patient's structural MR imaging study. All somatosensory responses (from the first, second, and third digit) across multiple trials projected onto the same axial slice in panel D. No interictal epileptiform discharges were recorded during the MEG.

younger patients included in these series. This raises the question of whether a potential benefit is not seen because surgery is delayed beyond a potentially important developmental window.

Second, we sought to identify those patients with TSC who might benefit from surgery even though they do not meet traditional criteria, as discussed above. Many patients with TSC have multiple potentially epileptogenic cortical tubers. Because the epilepsy in TSC is almost always partial in nature, we advocate using bilateral strip electrode surveys to detect one or more discrete regions of the brain that could be targets for epilepsy surgery. This technique has been previously described in detail. ${ }^{75}$

Third, we hope to improve the outcome of epilepsy surgery in TSC in general by identifying and defining the extent of the seizure foci in these children. Unfortunately, defining the margins of the epileptogenic zone has proven difficult in patients with TSC. Surgery may fail due to an adjacent or distant tuber/epileptogenic zone. Early work in this field was tempered by the outlook that multiple cortical tubers predict surgical failure. Thus, even if the main seizure focus is removed, seizures are likely to persist, driven by other tubers/seizure foci.

We have approached this challenge with a multistaged technique, in which 3 operations are performed during a single hospitalization. ${ }^{4}$ During Stage 1, electrodes are im- planted in the brain to detect the major seizure focus. During Stage 2, the seizure focus is removed and new electrodes are replaced to identify other areas of the brain that might continue to generate seizures. During Stage 3, any additional seizure foci are removed, in addition to the electrodes. The goal of this strategy is to identify unrecognized adjacent distal tubers/epileptogenic zones once the presumed major seizure focus has been removed in order to reduce surgical failures secondary to these other sites. In addition, a more conservative and possibly function-sparing strategy may be used during the initial resection, with further decisions made based on postresection invasive monitoring.

Disadvantages of the multistage approach include an additional operation with associated cost, length of stay, and potential morbidity. An alternative to this is a single- or 2-stage resection of the dominant tuber/seizure focus, with further surgery considered in the future only if seizures persist. However, we have found that it is simpler to carry out a more complete resection during the initial hospital stay rather than bring the child and family back at a later time. Another major question about the multistage approach concerns the clinical significance of seizures recorded between Stages 2 and 3, immediately following the initial resection. Although it is possible these events may dissipate over time, our experience suggests otherwise. In addition, sever- 
R. J. Bollo et al.
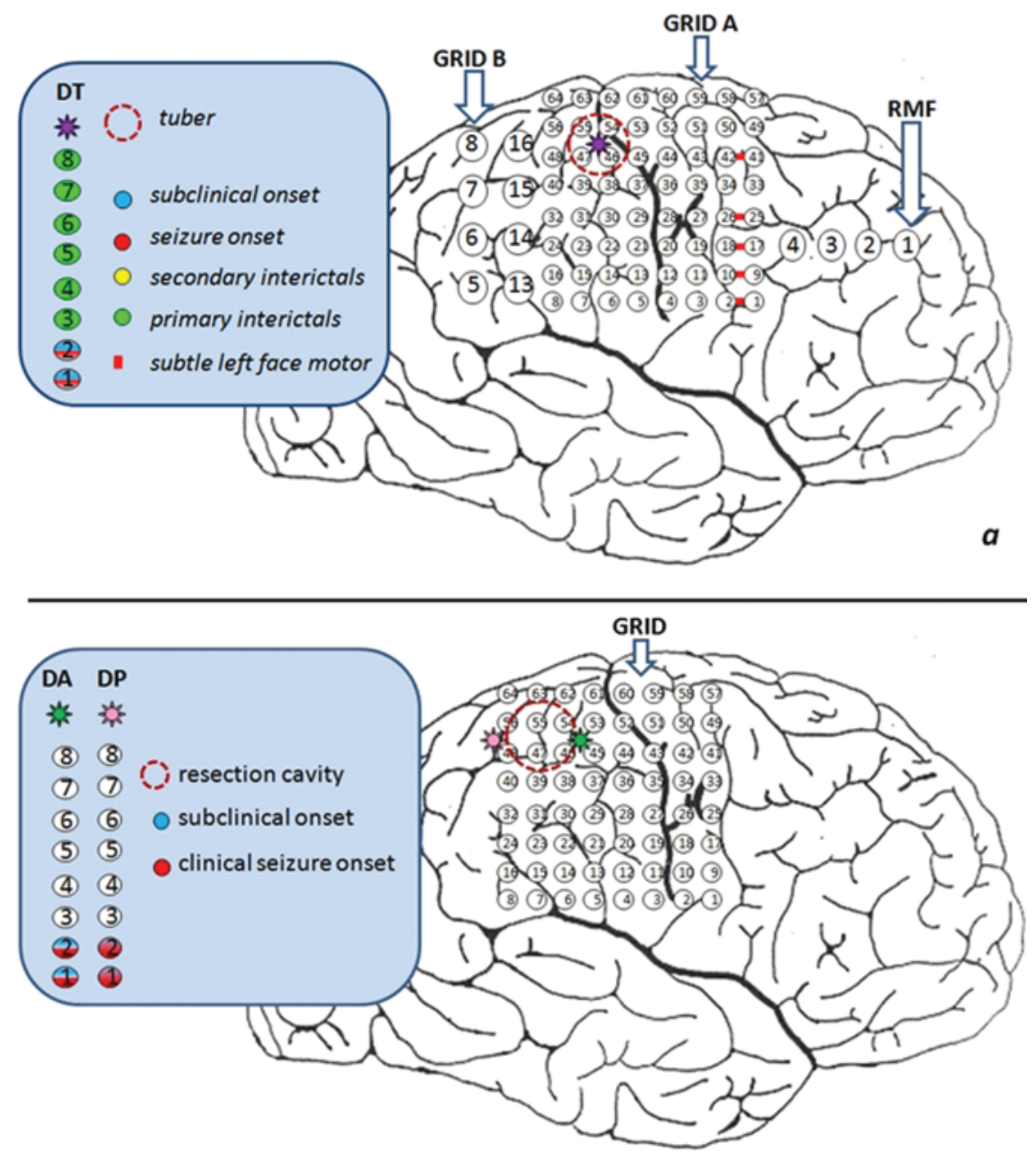

b

FIG. 5. Illustrative case. Ictal maps. a: Combined ictal and functional map obtained after the first video-EEG monitoring period (between Stages 1 and 2). The depth electrode shown in figure 3b is denoted by DT. Note ictal onset at distal contacts closest to mesial tubers (1-2), and the absence of seizure activity recorded by the grid overlying the lateral tuber. The RMF refers to a 4-contact strip placed over the right middle frontal gyrus beyond the craniotomy margin. (b) Ictal map after the second monitoring period (between Stages 2 and 3). The DA and DP correspond to depth electrodes targeting the anterior and posterior margins of the mesial resection cavity, respectively. Note persistent clinical and subclinical discharges from the anterior margin, with clinical seizures triggered by the posterior margin.

al studies have shown a correlation between early postresection seizures and poor outcome..$^{16,40,43}$

\section{Illustrative Case}

This 3.5-year-old boy with TSC presented with a history of 300 simple partial seizures per month, each described as a characteristic "stare" and clonic movements beginning in the left arm and progressing to the left leg and occasionally the right side. Multiple medications failed to treat the patient's condition. Physical examination revealed a mild left hemiparesis that was worse in the lower extremity. Magnetic resonance imaging demonstrated a large right central tuber located on the lateral surface of the hemisphere as well as a smaller posterior frontal tuber on the mesial surface and a hypointense area suspected of being a calcified tuber (Fig. 3a).
The preoperative evaluation included scalp video-EEG monitoring, PET with FDG and AMT, and MEG (Fig. 4). Interictal EEG revealed right centroparietal spikes and sharp waves prominent during sleep. Multiple clinical and subclinical seizures were captured, showing right centroparietal onsets. Magnetoencephalography did not detect any interictal epileptiform activity. The AMT-PET studies (performed at another institution) revealed diffusely increased uptake over a large area of the right hemisphere including temporal and parietal lobes, but they were unable to define a discrete epileptogenic zone. The patient's family sought several opinions and were given a broad range of treatment recommendations at various centers, including nonoperative management, single-stage resection of the dominant lateral tuber, or a 2-stage procedure with invasive monitoring via electrodes targeting regions implicated by PET. 

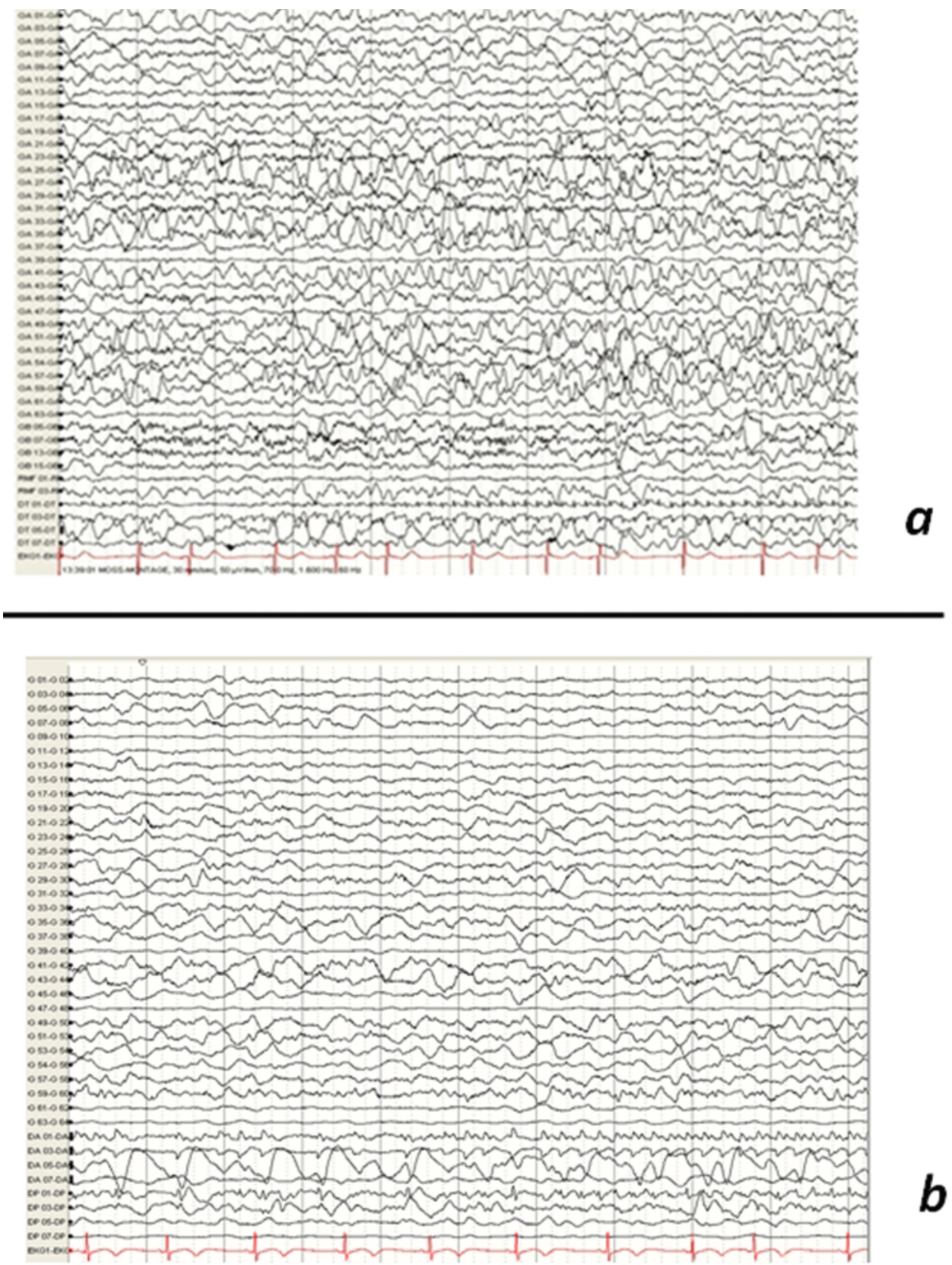

FIG. 6. Illustrative case. Video-EEG recordings. a: Recordings obtained during the first monitoring period (between Stages 1 and 2). Seizure onset, characterized by attenuation in DT1-2, followed by focal, low amplitude 7-Hz rhythmic spike and slow wave activity is visible in DT1-2 and DT3-4. b: Second monitoring period (between Stages 2 and 3). Seizure onset showing irregular spike and slow wave activity initially in DA1-2, DA3-4, DP1-2 and DP3-4. Evolution in the same channels to rhythmic 9-Hz activity is present with admixed epileptiform spikes. See Fig. 6 for definitions of the abbreviations.

After discussing the case at our multidisciplinary epilepsy conference, a surgical approach was offered. During the first stage, an electrode array was implanted consisting of a 64-contact grid (Adtech) over the lateral tuber, strip electrodes extending from the margins of the grid, and a depth electrode targeting the mesial tuber with frameless stereotactic guidance (Fig. 3b). Invasive monitoring demonstrated that the patient's typical seizures originated from the deepest mesial tuber with spread that involved the lateral lesion (Figs. 5a and 6a). Motor mapping revealed the lateral cortical tuber was located posterior to primary sensory cortex. During Stage 2, a resection of all 3 MR imagingdefined lesions was performed. A 64-contact grid and depth electrodes were reimplanted to determine if any epileptogenic tissue remained at the resection margins (Fig. 7). The postoperative MR image confirmed that all 3 lesions were removed, and showed the depth electrodes within the perituberal cortex (Fig. 3c). However, the patient 

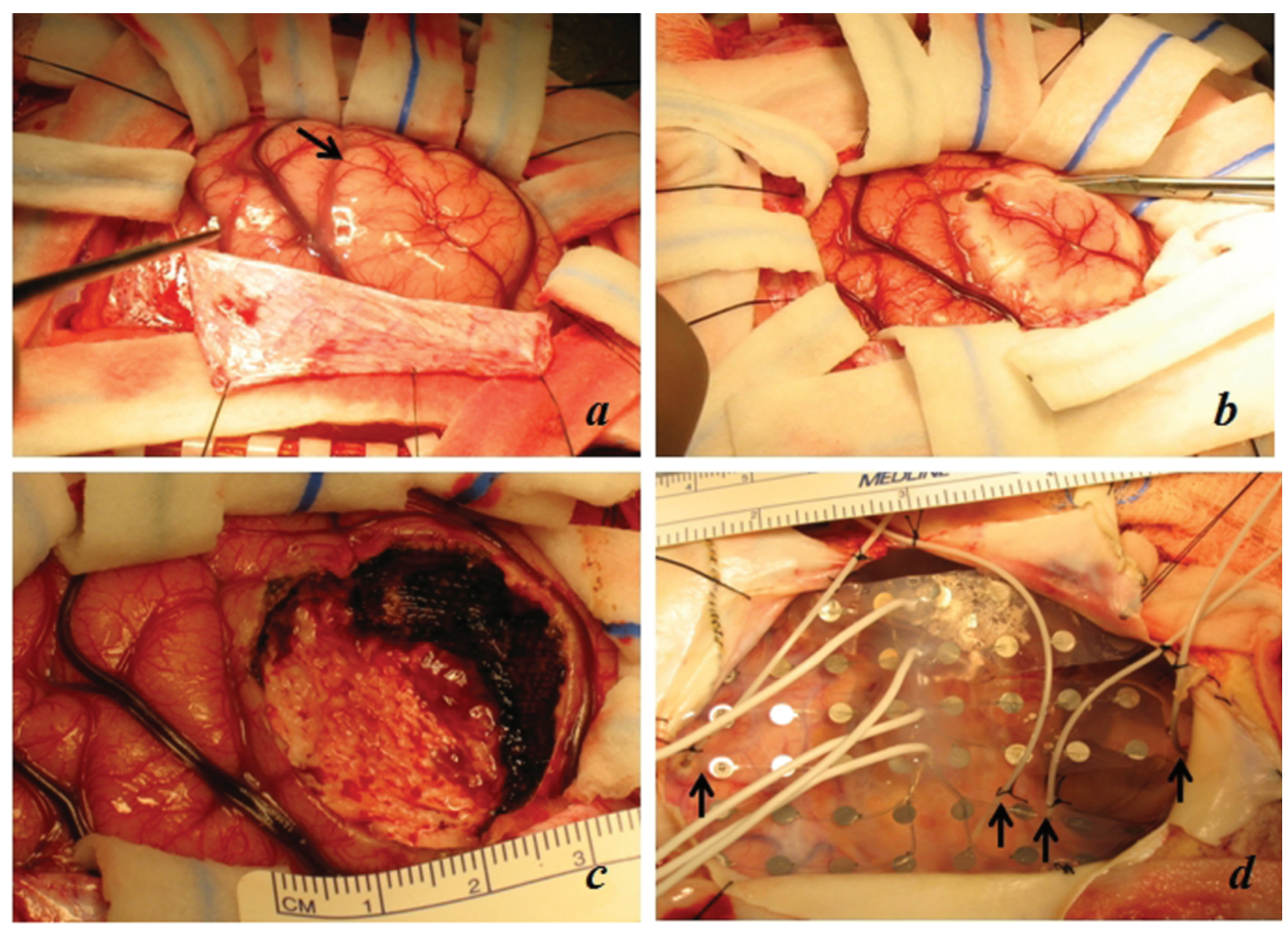

FIG. 7. Intraoperative photographs obtained during the second operative stage in a child with TSC who underwent multistage seizure focus resection with invasive monitoring. This patient has very similar pathology to the patient presented in the Case Illustration, and underwent treatment according to the same clinical paradigm. a: The right parietal tuber (arrow) is exposed after removal of intracranial electrodes. Note that the tuber is contained within a single gyrus, respecting sulcal anatomy. b: The tuber is outlined with bipolar cautery and resected according to standard microsurgical technique. c: The surgical cavity after tuber resection, prior to placement of intracranial electrodes for the second postoperative monitoring period. $\mathrm{d}$ : Cortex around tuber is covered with a 64-contact subdural grid electrode array. Depth electrodes (arrows) are placed through small holes cut in the grid into deep regions of interest by using frameless stereotactic guidance.

continued to experience seizures from the deep margins, as detected by the depth electrodes (Figs. 5b and 6b). This tissue was resected completely at the third and final operative stage.

Compared with his preoperative condition of multiple daily seizures, this child remains seizure free at 6 months after surgery, with improvement in motor function. Pathological analysis of the tissue removed at the final stage revealed abnormal TSC cells within the brain. This case illustrates a core observation in our experience: seizures may arise independently from the brain around the tuber targeted for resection rather than from a remote tuber. In our experience, lesionectomy alone has rarely been sufficient to stop seizures in these patients. In addition, this case highlights the utility of depth electrodes to study remote cortical regions of interest during invasive monitoring in patients with TSC.

\section{Current Results}

Our initial experience with 25 patients (median age 4.0 years, mean follow-up 28 months, and $68 \%$ seizure-free outcome) was reported previously. ${ }^{75}$ Between 1998 and the present, we have operated on 51 children between the ages of 7 months and 16 years. Many children were previously rejected as surgical candidates because they had multiple tubers and/or seizure foci. One patient was lost to followup, and 5 completed a diagnostic bilateral strip electrode survey without proceeding to resection. Thirty $(67 \%)$ of the remaining 45 children are seizure free, and 15 (33\%) are not.

There have been no deaths or permanent neurological deficits as a result of surgery. The mean monitoring time for patients undergoing multistage resection was 6.4 days for the first postoperative period, 4.7 days for the second, and 11.1 days total. Six patients suffered a transient post- 
operative hemiparesis that resolved within 2 months of surgery. One child developed hydrocephalus, requiring placement of a ventriculoperitoneal shunt, 1 child with a wound infection required reoperation, and 3 patients had partial resorption of the cranial bone flap. Four patients had positive intraoperative surveillance cultures without clinical evidence of meningitis; all were successfully treated with intravenous antibiotics. Some patients who are seizure free have not experienced robust neuropsychological gains, and many children who continue to suffer from seizures have shown dramatic neuropsychological improvements. However, in general, a correlation exists between seizure control and improved neuropsychological outcome. ${ }^{39,81}$

Twenty of 51 patients were in the worst of all prognostic categories. Because of their apparent multifocal epilepsy, they did not meet traditional surgical criteria. After extensive discussions among epilepsy team members and patients' families, these 20 patients underwent bilateral strip electrode surveys. Fifteen were found to have one or more seizure foci and, after careful evaluation, were offered resection. At current follow-up, 8 of these 15 children are seizure free. This cohort is being analyzed in detail to determine the ideal candidates for this approach and to identify factors on EEG and imaging that may predict success in identifying seizure foci.

Intracranial monitoring dictated further resection in most patients at the third stage. Moreover, all the initial surgical failures were due to insufficient resection of the epileptogenic tissue at the primary ictal onset zone. Five of the 51 children in our series underwent reoperation for recurrent seizures within the first 18 months after initial resection. Interestingly, all required further resection of epileptogenic tissue beginning at the margin of the prior resection, rather than resection of an anatomically remote tuber. Three of these 5 children remain seizure-free at most recent follow-up.

\section{Tubers And Epileptogenesis in TSC}

One advantage of the multistage approach is the unique opportunity to study the origin of epilepsy in children with TSC, which has facilitated a better understanding of the complex relationship of the tuber to the epileptogenic zone. Indeed, some patients with TSC have multiple seizure foci in different brain regions documented by intracranial electrode studies and required resection in different areas of the brain. Rarely, we have removed seizure foci from distinct regions of either hemisphere. ${ }^{57}$ However, 2 consistent observations in our practice include that distant tubers infrequently lead to surgical failure, and the dominant epileptogenic zone often extends beyond the tuber margin.

Our results have led us to question the dogma that the primary target for resection in TSC is the tuber. This concept presumes tubers are intrinsically epileptogenic lesions. Are tubers really the origin of seizures in TSC? The concept that seizures may originate within tubers is based on several factors, the most obvious being that they are lesions within the brain, which have traditionally been presumed to be the ictal source, be they neoplastic, vascular, or developmental malformations. Focal cortical dysplasia lesions are known to be intrinsically epileptogenic, and balloon cells in focal cortical dysplasia share similarities with giant cells in tubers. ${ }^{78}$ This includes frequent genetic alterations in $T S C 1^{6}$ and diminished hamartin and tuberin expression ${ }^{17}$ observed in focal cortical dysplasia balloon cells from epilepsy resection specimens.

Furthermore, some have observed interictal epileptiform discharges within tubers during intraoperative recording, and the resection of tubers associated with epileptiform activity has led to diminished seizure frequency. $3,5,8,18$. 26-28,34,35,37,41,52,57,75 However, little direct evidence in the literature supports a clear correlation between the seizure focus and the tuber. Moreover, analysis of several surgical descriptions in the literature reveals that cortex adjacent to tubers is often resected during "tuberectomy." 34,35,37,41,52,57,75 Finally, many patients with a large "tuber burden" seen on MR images do not have seizures at all and often come to neurosurgical attention only because of other TSC-associated lesions, such as the growth of a subependymal giant cell astrocytoma.

Efforts to understand the molecular pathogenesis of structural (cortical tubers) and electrophysiological (seizure) abnormalities that characterize TSC have focused on the development of animal models. ${ }^{63}$ The Eker rat, which carries a spontaneous heterozygous mutation of the TSC2 gene, shows mild cortical pathology but does not develop spontaneous seizures. ${ }^{76}$ In addition, manipulation of the TSC1 and TSC2 genes in rodents has not led to tuber formation. Homozygous knockout mutations of TSCl or TSC2 are embryonic lethal, and mice heterozygous for TSC1 or TSC2 do not develop tubers or spontaneous seizures. ${ }^{48,76}$

Conditional TSC1 knockout in mouse astrocytes leads to seizures and hippocampal disorganization. ${ }^{67}$ Disruption of TSC1 expression in neurons leads to spontaneous seizures as well as ectopic, enlarged neurons resembling giant cells. ${ }^{44}$ However, Wang and colleagues ${ }^{74}$ found no tubers when they analyzed mice lacking neuronal expression of TSC1 in a synapsin-TSCl conditional knockout. Evidence that disruption of hamartin/tuberin signaling in neurons and astrocytes may cause seizures in the absence of tubers supports the hypothesis that the brain may be hyperexcitable in TSC even in the absence of tubers.

Analysis of the TSC literature reveals the convergence of data from functional imaging with MEG and PET and electrophysiological data from EEG, implicating the margins of the tuber as independently epileptogenic. ${ }^{9,32,33,41,80}$ The intracranial electrode recordings in our series have enabled us to begin to address this question directly in humans in vivo.

\section{Conclusions}

Our experience has demonstrated that epilepsy surgery for patients with TSC can be successful even in the absence of a single apparent seizure focus, removal of the tuber alone is often insufficient for seizure control, and many good surgical candidates may be identified with bilateral strip electrode surveys, despite failure to identify the primary ictal focus by noninvasive testing. Several centers now consider the possibility that select patients with TSC without a single dominant tuber/epileptogenic focus in whom all medical therapy has failed may be surgical candidates, particularly if no other viable treatment options exist. The treating team of specialists in close cooperation 
with the patient's family must determine whether the potential benefits of surgery outweigh the risks of the surgery itself as well as persistent refractory epilepsy.

\section{Disclaimer}

None of the authors have any financial interest in any of the material presented in this manuscript.

\section{References}

1. Ahnlide JA, Rosén I, Lindén-Mickelsson Tech P, Källén K: Does SISCOM contribute to favorable seizure outcome after epilepsy surgery? Epilepsia 48:579-588, 2007

2. Asano E, Chugani DC, Muzik O, Shen C, Juhász C, Janisse J, et al: Multimodality imaging for improved detection of epileptogenic foci in tuberous sclerosis complex. Neurology 54:19761984, 2000

3. Avellino A, Berger MS, Rostomily RC, Shaw CM, Ojemann GA: Surgical management and seizure outcome in patients with tuberous sclerosis. J Neurosurg 87:391-396, 1997

4. Bauman JA, Feoli E, Romanelli P, Doyle WK, Devinsky O, Weiner HL: Multistage epilepsy surgery: safety, efficacy, and utility of a novel approach in pediatric extratemporal epilepsy. Neurosurgery 56:318-354, 2005

5. Bebin EM, Kelly PJ, Gomez MR: Surgical treatment for epilepsy in cerebral tuberous sclerosis. Epilepsia 34:651-657, 1993

6. Becker AJ, Urbach H, Scheffler B, Baden T, Normann S, Lahl R, et al: Focal cortical dysplasia of Taylor's balloon cell type: mutational analysis of the TSC1 gene indicates a pathogenic relationship to tuberous sclerosis. Ann Neurol 52:29-37, 2002

7. Bruce DA, Bizzi JW: Surgical technique for the insertion of grids and strips for invasive monitoring in children with intractable epilepsy. Childs Nerv Syst 16:724-730, 2000

8. Bye AM, Matheson JM, Tobias VH, Mackenzie RA: Selective epilepsy surgery in tuberous sclerosis. Aust Paediatr J 25: 243-245, 1989

9. Chandra PS, Salamon N, Huang J, Wu JY, Koh S, Vinters HV, et al: FDG-PET/MRI coregistration and diffusion-tensor imaging distinguish epileptogenic tubers and cortex in patients with tuberous sclerosis complex: a preliminary report. Epilepsia 47: 1543-1549, 2006

10. Chugani DC, Chugani HT, Muzik O, Shah JR, Shah AK, Canady A, et al: Imaging epileptogenic tubers in children with tuberous sclerosis complex using alpha-[11C]methyl-L-tryptophan positron emission tomography. Ann Neurol 44:858-866, 1998

11. Chugani HT: What can we learn from functional neuroimaging in children? Indian Pediatr 43:203-206, 2006

12. Chugani HT, Shields WD, Shewman DA, Olson DM, Phelps ME, Peacock WJ: Infantile spasms: I. PET identifies focal cortical dysgenesis in cryptogenic cases for surgical therapy. Ann Neurol 27:406-413, 1990

13. Crino PB, Nathanson KL, Henske EP: The tuberous sclerosis complex. N Engl J Med 355:1345-1356, 2006

14. Cross JH, Jayakar P, Nordli D, Delalande O, Duchowny M, Wieser HG, et al: Proposed criteria for referral and evaluation of children for epilepsy surgery: recommendations of the Subcommission for Pediatric Epilepsy Surgery. Epilepsia 47: 952-959, 2006

15. Duncan JD, Moss SD, Bandy DJ, Manwaring K, Kaplan AM, Reiman EM, et al: Use of positron emission tomography for presurgical localization of eloquent brain areas in children with seizures. Pediatr Neurosurg 26:144-156, 1997

16. Garcia PA, Barbaro NM, Laxer KD: The prognostic value of postoperative seizures following epilepsy surgery. Neurology 41: 1511-1512, 1991

17. Grajkowska W, Kotulska K, Matyja E, Larysz-Brysz M, Mandera M, Roszkowski M, et al: Expression of tuberin and hamartin in tuberous sclerosis complex-associated and sporadic cortical dys- plasia of Taylor's balloon cell type. Folia Neuropathol 46:43-48, 2008

18. Guerreiro MM, Andermann F, Andermann E, Palmini A, Hwang P, Hoffman HJ, et al: Surgical treatment of epilepsy in tuberous sclerosis: strategies and results in 18 patients. Neurology 51: 1263-1269, 1998

19. Hardin CO, Pagon RA: Incidence of tuberous sclerosis in patients with cardiac rhabdomyoma. Am J Med Genet 37:443-446, 1992

20. Harvey AS, Freeman JL: Epilepsy in hypothalamic hamartoma: clinical and EEG features. Semin Pediatr Neurol 14:60-64, 2007

21. Hirsch LJ, Spencer SS, Spencer DD, Williamson PD, Mattson RH: Temporal lobectomy in patients with bitemporal epilepsy defined by depth electroencephalography. Ann Neurol 30: 347-356, 1991

22. Hodges AK, Li S, Maynard J, Parry L, Braverman R, Cheadle JP, et al: Pathological mutations in TSC1 and TSC2 disrupt the interaction between hamartin and tuberin. Hum Mol Genet 10: 2899-2905, 2001

23. Iida K, Otsubo H, Mohamed IS, Okuda C, Ochi A, Weiss SK, et al: Characterizing magnetoencephalographic spike sources in children with tuberous sclerosis complex. Epilepsia 46:15101517,2005

24. Jacobs J, Rohr A, Moeller F, Boor R, Kobayashi E, LeVan Meng $\mathrm{P}$, et al: Evaluation of epileptogenic networks in children with tuberous sclerosis complex using EEG-fMRI. Epilepsia 49: 816-825, 2008

25. Jansen FE, Huiskamp G, van Huffelen AC, Bourez-Swart M, Boere E, Gebbink T, et al: Identification of the epileptogenic tuber in patients with tuberous sclerosis: a comparison of high-resolution EEG and MEG. Epilepsia 47:108-114, 2006

26. Jansen FE, van Huffelen AC, Algra A, van Nieuwenhuizen O: Epilepsy surgery in tuberous sclerosis: a systematic review. Epilepsia 48:1477-1484, 2007

27. Jansen FE, van Huffelen AC, Van Rijen PC, Leijten FS, Jennekens-Schinkel A, Gosselaar P, et al: Epilepsy surgery in tuberous sclerosis: the Dutch experience. Seizure 16:445-453, 2007

28. Jarrar RG, Buchhalter JR, Raffel C: Long-term outcome of epilepsy surgery in patients with tuberous sclerosis. Neurology 62: 479-481, 2004

29. Jayakar P: Invasive EEG monitoring in children: when, where, and what? J Clin Neurophysiol 16:408-418, 1999

30. Jones AC, Shyamsundar MM, Thomas MW, Maynard J, Idziaszczyk S, Tomkins $\mathrm{S}$, et al: Comprehensive mutation analysis of TSC1 and TSC2 and phenotypic correlations in 150 families with tuberous sclerosis. Am J Hum Genet 64:1305-1315, 1999

31. Juhász C, Chugani HT: Imaging the epileptic brain with positron emission tomography. Neuroimaging Clin N Am 13:705-716, 2003

32. Kagawa K, Chugani DC, Asano E, Juhász C, Muzik O, Shah A, et al: Epilepsy surgery outcome in children with tuberous sclerosis complex evaluated with alpha-[11C]methyl-L-tryptophan positron emission tomography (PET). J Child Neurol 20: 429-438, 2005

33. Kamimura T, Tohyama J, Oishi M, Akasaka N, Kanazawa O, Sasagawa M, et al: Magnetoencephalography in patients with tuberous sclerosis and localization-related epilepsy. Epilepsia 47: 991-997, 2006

34. Karenfort M, Kruse B, Freitag H, Pannek H, Tuxhorn I: Epilepsy surgery outcome in children with focal epilepsy due to tuberous sclerosis complex. Neuropediatrics 33:255-261, 2002

35. Koh S, Jayakar P, Dunoyer C, Whiting SE, Resnick TJ, Alvarez LA, et al: Epilepsy surgery in children with tuberous sclerosis complex: presurgical evaluation and outcome. Epilepsia 41:1206-1213, 2000

36. Kwiatkowska J, Wigowska-Sowinska J, Napierala D, Slomski R, Kwiatkowski DJ: Mosaicism in tuberous sclerosis as a potential cause of the failure of molecular diagnosis. N Engl J Med 340: 
703-707, 1999

37. Lachhwani DK, Pestana E, Gupta A, Kotagal P, Bingaman W, Wyllie E: Identification of candidates for epilepsy surgery in patients with tuberous sclerosis. Neurology 64:1651-1654, 2005

38. Levy M, Feingold J: Estimating prevalence in single-gene kidney diseases progressing to renal failure. Kidney Int 58:925-943, 2000

39. Loddenkemper T, Holland KD, Stanford LD, Kotagal P, Bingaman W, Wyllie E: Developmental outcome following epilepsy surgery in infancy. Pediatrics 119:930-935, 2007

40. Lüders H, Murphy D, Awad I, Wyllie E, Dinner DS, Morris HH III, et al: Quantitative analysis of seizure frequency 1 week and 6, 12, and 24 months after surgery of epilepsy. Epilepsia 35: 1174-1178, 1994

41. Madhavan D, Schaffer S, Yankovsky A, Arzimanoglou A, Renaldo F, Zaroff, CM, et al: Surgical outcome in tuberous sclerosis complex: a multicenter survey. Epilepsia 48:1625-1628, 2007

42. Madhavan D, Weiner HL, Carlson C, Devinsky O, Kuzniecky R: Local epileptogenic networks in tuberous sclerosis complex: a case review. Epilepsy Behav 11:140-146, 2007

43. Mani J, Gupta A, Mascha E, Lachhwani D, Prakash K, Bingaman $\mathrm{W}$, et al: Postoperative seizures after extratemporal resections and hemispherectomy in pediatric epilepsy. Neurology 66:10381043, 2006

44. Meikle L, Talos DM, Onda H, Pollizzi K, Rotenberg A, Sahin M, et al: A mouse model of tuberous sclerosis: neuronal loss of Tsc1 causes dysplastic and ectopic neurons, reduced myelination, seizure activity, and limited survival. J Neurosci 27:5546-5558, 2007

45. Nellist M, Verhaaf B, Goedbloed MA, Reuser AJ, van den Ouweland AM, Halley DJ: TSC2 missense mutations inhibit tuberin phosphorylation and prevent formation of the tuberin-hamartin complex. Hum Mol Genet 10:2889-2898, 2001

46. Niida Y, Lawrence-Smith N, Banwell A, Hammer E, Lewis J, Beauchamp RL, et al: Analysis of both TSC1 and TSC2 for germline mutations in 126 unrelated patients with tuberous sclerosis. Hum Mutat 14:412-422, 1999

47. Northrup H, Wheless JW, Bertin TK, Lewis RA: Variability of expression in tuberous sclerosis. J Med Genet 30:41-43, 1993

48. Onda H, Crino PB, Zhang H, Murphey RD, Rastelli L, Gould Rothberg BE, et al: Tsc2 null murine neuroepithelial cells are a model for human tuber giant cells, and show activation of an mTOR pathway. Mol Cell Neurosci 21:561-574, 2002

49. Osborne JP, Fryer A, Webb D: Epidemiology of tuberous sclerosis. Ann N Y Acad Sci 615:125-127, 1991

50. Papanicolaou AC, Pataraia E, Billingsley-Marshall R, Castillo EM, Wheless JW, Swank P, et al: Toward the substitution of invasive electroencephalography in epilepsy surgery. J Clin Neurophysiol 22:231-237, 2005

51. Parain D, Penniello MJ, Berquen P, Delangre T, Billard C, Murphy JV: Vagal nerve stimulation in tuberous sclerosis complex patients. Pediatr Neurol 25:213-216, 2001

52. Perot P, Weir B, Rasmussen T: Tuberous sclerosis. Surgical therapy for seizures. Arch Neurol 15:498-506, 1966

53. Pirotte B, Goldman S, Salzberg S, Wikler D, David P, Vandesteene A, et al: Combined positron emission tomography and magnetic resonance imaging for the planning of stereotactic brain biopsies in children: experience in 9 cases. Pediatr Neurosurg 38:146-155, 2003

54. Roach ES, DiMario FJ, Kandt RS, Northrup H: Tuberous Sclerosis Consensus Conference: recommendations for diagnostic evaluation. National Tuberous Sclerosis Assocation. J Child Neurol 14:401-407, 1999

55. Roach ES, Gomez MR, Northrup H: Tuberous sclerosis complex consensus conference: revised clinical diagnostic criteria. J Child Neurol 13:624-628, 1998

56. Robertson RL, Glasier CM: Diffusion-weighted imaging of the brain in infants and children. Pediatr Radiol 37:749-768, 2007

57. Romanelli P, Weiner HL, Najjar S, Devinsky O: Bilateral resec- tive epilepsy surgery in a child with tuberous sclerosis: case report. Neurosurgery 49:732-735, 2001

58. Rose VM, Au KS, Pollom G, Roach ES, Prashner HR, Northrup $\mathrm{H}$ : Germ-line mosaicism in tuberous sclerosis: how common? Am J Hum Genet 64:986-992, 1999

59. Rowley SA, O'Callaghan FJ, Osborne JP: Ophthalmic manifestations of tuberous sclerosis: a population based study. Br J Ophthalmol 85:420-423, 2001

60. Sampson JR, Harris PC: The molecular genetics of tuberous sclerosis. Hum Mol Genet 3:1477-1480, 1994

61. Schiller Y, Cascino GD, Sharbrough FW: Chronic intracranial EEG monitoring for localizing the epileptogenic zone: an electroclinical correlation. Epilepsia 39:1302-1308, 1998

62. Schwartz RA, Fernández G, Kotulska K, Józwiak S: Tuberous sclerosis complex: advances in diagnosis, genetics, and management. J Am Acad Dermatol 57:189-202, 2007

63. Schwartzkroin PA, Walsh CA: Cortical malformations and epilepsy. Ment Retard Dev Disabil Res Rev 6:268-280, 2000

64. Smalley SL, Burger F, Smith M: Phenotypic variation of tuberous sclerosis in a single extended kindred. J Med Genet 31:761-765, 1994

65. Sood S, Chugani HT: Functional neuroimaging in the preoperative evaluation of children with drug-resistant epilepsy. Childs Nerv Syst 22:810-820, 2006

66. Tee AR, Fingar DC, Manning BD, Kwiatkowski DJ, Cantley LC, Blenis J: Tuberous sclerosis complex-1 and -2 gene products function together to inhibit mammalian target of rapamycin (mTOR)-mediated downstream signaling. Proc Natl Acad Sci U S A 99:13571-13576, 2002

67. Uhlmann EJ, Wong M, Baldwin RL, Bajenaru ML, Onda H, Kwiatkowski DJ, et al: Astrocyte-specific TSC1 conditional knockout mice exhibit abnormal neuronal organization and seizures. Ann Neurol 52:285-296, 2002

68. van Slegtenhorst M, de Hoogt R, Hermans C, Nellist M, Janssen $\mathrm{B}$, Verhoef $\mathrm{S}$, et al: Identification of the tuberous sclerosis gene TSC1 on chromosome 9q34. Science 277:805-808, 1997

69. van Slegtenhorst M, Nellist M, Nagelkerken B, Cheadle J, Snell R, van den Ouweland $\mathrm{A}$, et al: Interaction between hamartin and tuberin, the TSC 1 and TSC2 gene products. Hum Mol Genet 7: 1053-1057, 1998

70. Verhoef S, Bakker L, Tempelaars AM, Hesseling-Janssen AL, Mazurczak T, Jozwiak S, et al: High rate of mosaicism in tuberous sclerosis complex. Am J Hum Genet 64: 1632-1637, 1999

71. Webb DW, Clarke A, Fryer A, Osborne JP: The cutaneous features of tuberous sclerosis: a population study. Br J Dermatol 135:1-5, 1996

72. Webb DW, Fryer AE, Osborne JP: Morbidity associated with tuberous sclerosis: a population study. Dev Med Child Neurol 38:146-155, 1996

73. Webb DW, Thomas RD, Osborne JP: Cardiac rhabdomyomas and their association with tuberous sclerosis. Arch Dis Chil 68:367-370, 1993

74. Wang Y, Greenwood JS, Calcagnotto ME, Kirsch HE, Barbaro NM, Baraban SC: Neocortical hyperexcitability in a human case of tuberous sclerosis complex and mice lacking neuronal expression of TSC1. Ann Neurol 61:139-152, 2007

75. Weiner HL, Carlson C, Ridgway EB, Zaroff CM, Miles D, LaJoie $\mathrm{J}$, et al: Epilepsy surgery in young children with tuberous sclerosis: results of a novel approach. Pediatrics 117:1494-1502, 2006

76. Wenzel HJ, Patel LS, Robbins CA, Emmi A, Yeung RS, Schwartzkroin PA: Morphology of cerebral lesions in the Eker rat model of tuberous sclerosis. Acta Neuropathol 108:97-108, 2004

77. Wheless JW, Willmore LJ, Breier JI, Kataki M, Smith JR, King DW, et al: A comparison of magnetoencephalography, MRI, and V-EEG in patients evaluated for epilepsy surgery. Epilepsia 40:931-941, 1999

78. Wong M: Mechanisms of epileptogenesis in tuberous sclerosis complex and related malformations of cortical development with 


\section{R. J. Bollo et al.}

abnormal glioneuronal proliferation. Epilepsia 49:8-21, 2008

79. Wyllie E, Lachhwani DK, Gupta A, Chirla A, Cosmo G, Worley S, et al: Successful surgery for epilepsy due to early brain lesions despite generalized EEG findings. Neurology 69:389-397, 2007

80. Wu JY, Sutherling WW, Koh S, Salamon N, Jonas R, Yudovin S, et al: Magnetic source imaging localizes the epileptogenic zone in children with tuberous sclerosis complex. Neurology 66: 1270-1272, 2006

81. Zaroff CM, Morrison C, Ferraris N, Weiner HL, Miles DK,
Devinsky O: Developmental outcome of epilepsy surgery in tuberous sclerosis complex. Epileptic Disord 7:321-326, 2005

Manuscript submitted May 15, 2008.

Accepted June 25, 2008.

Address correspondence to: Robert J. Bollo, M.D., Department of Neurosurgery, New York University Langone Medical Center, 550 First Avenue, New York, New York 10016. email: robert.bollo@nyumc.org. 